\title{
Institutional, Financial and Digital Aspects of the Ethical Entrepreneurship Structure in Ecological Economics
}

\author{
Yuri A. Levin ${ }^{1 *[O R C I D}$ 0000-0002-9568-7866], \\ Olga P. Ivanova 2[ORCID 0000-0002-9563-4166], \\ Galina Yu. Fomina 3[ORCID 0000-0003-1140-5778], \\ Andrey V. Volkov 4[ORCID 0000-0002-1827-5606]
}

\author{
${ }^{1}$ Moscow State Institute of International Relations (MGIMO University), Moscow, Russia \\ ${ }^{2}$ Yaroslav-the-Wise Novgorod State University, Veliky Novgorod, Russia \\ ${ }^{3}$ Russian Presidential Academy of National Economy and Public Administration, Moscow, Russia \\ ${ }^{4}$ International Industrial Academy, Moscow, Russia \\ u.levin@odin.mgimo.ru
}

\begin{abstract}
The relevance of the research is due to the role of ethical entrepreneurship in a green economy, the increasing need for an ethical justification of the attitude to nature, the transition to the production and consumption of environmentally friendly products in the conditions of the growing global environmental danger of the formation of a technogenic type of economic development. The main characteristics of ethical entrepreneurship and its practical role in a green economy are highlighted. It is shown that the driving forces of the global green economy agenda are governments, investors, society (consumers), central banks. The structure of ethical entrepreneurship is presented as a set of strategic analysis institutions, financial institutions, business models and digital platforms that form management decisions for sustainable development and ESG implementation. It is shown that the financial assessment of the ESG strategy is based on the perception of the environmental component of entrepreneurial ethics as an image element of business culture and a form of environmental responsibility. The authors proposed to consider the digital platform as an information and economic structure that ensures the organization of algorithmic effective interaction of its participants at the expense of its own information infrastructure. It is stated that the ecosystem's supply chain is fragmented, and therefore it is necessary to create a digital platform to unite all participants in responsible investing in the ESG format. The universal possibilities of digital twins with the mutual influence of the subjects of the ethical entrepreneurship system are given. The possibilities of creating a "digital twin" of state policy and business policy for regulating the ecological type of financing ecosystems in the context of strategies for sustainable growth of the national economy, regions and industries based on optional modeling are identified.
\end{abstract}

Keywords: ecological mode, environmental management ethics, "green” finance, ESG strategy, digital twin

\section{INTRODUCTION}

Environmental protection remains one of the most urgent tasks. The solution of this task corresponds to both the United Nations Sustainable Development Goals (UN SDGs) adopted by all UN Member States in 2015. So are the goals of the Paris Agreement on curbing global warming and reducing greenhouse gas emissions. In the context of the pandemic, most advanced economies have begun to pay more attention to the issues of life-support ecosystems and biological diversity. Thus, one of the main directions of foreign policy activity of J. Biden's first hundred days were environmental issues. As part of this agenda, a climate summit was held as an attempt to fulfill its election promises, at 
which serious emission reductions were announced in the current decade. In July 2021 the International Financial Congress session was entirely devoted to the "green" theme, namely, the role of the financial sector in the global transition to a green economy.

The conception of a "green" economy, which justified the need for eco-production, was formed at the end of the twentieth century. The author of the conception is considered to be the American economist-ecologist G. Daly. In 1990, G. Daly proposed the basic rules for optimizing the use of natural resources and preserving the quality of the environment [1].

In recent years, there has been an evolution of society, business and government views on the ethics of natural resources rational use. The social responsibility of the business community and the ethics of environmental management led to the formation of entrepreneurial ethics conception. The further development of entrepreneurship ethics required appropriate social, technological, financial, institutional innovations that define the features of a new ecological mode of life, the type of consumption corresponding to it, productive forces and industrial relations, the use of accumulated knowledge and experience of environmental greening. Entrepreneurial ethics, as an integral part of environmental management ethics, representing a set of moral norms and principles of the mechanism of counterparties interaction, is one of the factors of demand growth and transition to the path of sustainable economy growth. The conception of sustainable growth, considering the problems of economic, environmental and social nature in the close interrelation of the issues of synthesis of management and policy, philosophical analysis has become decisive in the long-term development of the economies of developed countries [2].

The relevance of sustainable development concepts and the understanding of them by various business structures and the government have certainly increased in many countries in connection with the pandemic. The economic consequences of the crisis associated with the COVID-19 pandemic will be primarily qualitative, changing the quality and lifestyle of billions of people, as opposed to quantitative consequences due to periodic economic collapses. The formation of the perception of moral regulation also means the recognition of the existing dependence of the future development of society on the ecological mode.

Coupled with the mass formation of ecological consciousness, the "green" transformation creates new opportunities, leading not only to an increase in demand for ecologically produced products in the markets of most countries, but also to the transformation of many social relations, and as a result to the perception by society as a whole of the fact that the quality of life is directly related to the "green" financing of modern eco-production, the need for a systematic study of the possibilities and problems of information support related to ecological practice [3].

The term "green" finance covers both a wide range of ways to invest technological processes, projects and companies related to environmental protection, preservation of the integrity of natural ecosystems, and financial products (tools) and services with an environmental component, thanks to which the "green" agenda can become part of the business model of Russian enterprises in various sectors of the economy [4].

\section{MATERIALS AND METHODS}

The purpose of the article is to study the foundations of the formation of ethical entrepreneurship in the ecological economy. The tasks set by the authors are to substantiate the financial, institutional and digital aspects of ethical entrepreneurship. The study was conducted on the basis of a dialectical method. Using this method assumes that all events related to the formation of entrepreneurial ethics are in development and are inextricably linked between the causes of the formation of an ecological economy and possible results. In addition, special methods were used. Such as analysis and synthesis, as well as abstract-logical methods associated with the creation of digital models that have the most characteristic essential features of the system under study.

The research is based on the analysis of the relationship between economic growing and environmental problems, contained in the works of representatives of the classical economic school and the neoclassical direction. The formation of the author's idea of the influence of entrepreneurial ethics on the green economy was influenced by V. Vernadsky and P. Florensky, as well as the study of the actual problems of ecological and economic development $[5,6]$.

\section{RESULTS}

Regardless of the object of study, all possible approaches to the development of financial standards for the "green" transition are associated 
with the creation of a line of "green" products that will be in demand. The financial assessment of this transition strategy should be based on the perception of the environmental component of entrepreneurial ethics as an obligatory component of sustainable development and investment from public and private sources in the development and implementation of projects and programs to support industrial and regional ecosystems during the transition to a new technological mode [7]. In order to enhance the role of the financial system in risk management and to mobilize capital for investing in green projects, a Community of Central Banks and Supervisory Authorities was established in 2017 to improve the environmental Friendliness of the financial system and accelerate the process of Expanding the Scale of green finance (NGFS). Currently, NGFS consists of 95 members (more than 60 central banks, including the Central Bank of the Russian Federation) and 15 observers. The purpose of NGFS is to contribute to the strengthening and adoption at the global level of the measures necessary to achieve the goals of the Paris Climate Agreement. The main activities of the NGFS community are prudential regulation of the risks of financial organizations in the green economy, macro-financing of the stimulation and development of green banking, with the elimination of data gaps and research on the transition to responsible investment, taking into account the impact of selected investment objects on the environment.

For the Russian business community, ESG (ecology, social, governance) is an exceptionally new direction. At the same time, its growth in the West forces Russian corporations to follow global trends. ESG factors are environmental factors, social factors, and management factors. One of the world principles of responsible investment is to check the company for compliance with the principles of ESG. The ESG management system also includes national and international institutions for audit and remuneration, appointments, etc.

ESG approaches were formulated by the UN more than 15 years ago and are enshrined in the document "Principles of Responsible Investment" consisting of 17 positions, nine of which relate to ecology. The financial sector should play a stimulating role, while banks, together with the regulator, should create incentives for the development of eco-production and help companies find financing by following the ESG agenda. The demand for ESG financing tools is very high all over the world and in terms of its popularity, ESG can be compared with the assessment of a credit rating, one of the key indicators for investors. Against the background of the COVID-19 pandemic, the growth of investors in ESG indices is growing, as evidenced by the stable growth of portfolios with ESG factors. The main areas of regulation of ESG instruments are regulation of disclosure of non-financial information on accounting for ESG factors by large non-public companies, regulation of information disclosure on accounting for ESG factors and risks, taxonomy of green activities, tools, products, regulation of trade in carbon units, as well as, as noted above, prudential regulation of ESG risks by financial organizations and the creation of mechanisms to stimulate the development of the sustainable financing market.

In Russia, the main institutions involved in the development of criteria for determining sustainable development projects and the formation of a methodological framework for the verification of "green" tools include the Bank of Russia, the Ministry of Economic Development of Russia and VEB. The Russian Federation, as well as a special working group to coordinate the preparation of specific proposals for sustainable development. The launch of Russian instruments to stimulate the ESG agenda can be considered the beginning of the issue of "green bonds" in 2018 and the adoption of Regulation No. 706-P of December 19, 2019 "On standards for the issue of securities", which provided issuers with the opportunity to issue "green" and social bonds. However, such bonds, which have been issued only 3 times over the years, cannot yet be classified as financial instruments of "green" financing due to the lack of clear parameters, therefore they are of the nature of marketing or branding.

In the process of assessing the capabilities of the system of "green" financing instruments, it is necessary to develop approaches to assessing the mutual influence of its subjects as subsystems: federal and regional government bodies, scientific and educational institutions, enterprises of the industrial, energy, agricultural sector of the economy, trade, transport, finance, society. Therefore, the authors propose as a basic approach to divide all the indicators of subsystems into groups, and the groups, in turn, are ranked according to their degree of importance. For example, the results of its contribution to the economy, the health of the nation, the quality of the environment, demographic development and global integration, investment processes and technological development are critically important for assessing the subsystem "entrepreneurial ethics". These indicators affect the 
image of the business, the growth of investment attractiveness and government support measures, as well as the increasing number of new jobs [8]. When assessing the effect of entrepreneurial ethics, it is important to identify imperative requirements in the field of prudential supervision to stimulate financing programs that can orient business to eco-production. Such requirements imply the development and adoption of a set of rules on "green" lending, the subject of regulation of which should be banks and non-bank financial institutions. The main requirements of the set of rules may include: the obligation to conduct before issuing a loan, due diligence procedures for environmental and social risks, development, a stricter procedure for approving a loan when lending to companies from "polluting industries", a ban on issuing loans to borrowers who do not comply with environmental and social risk requirements, a detailed assessment by banks of the portfolio of "green" loans every 2 years and the provision of a final report. Judging by world experience, such sets of rules and their corresponding programs are beginning to develop. For example, in China. They will determine the creation of a new ecological and technological way of life in 5-20 years in the world, and already now the strategic guidelines of the new way of life allow us to identify digital solutions. It is known that the concept of "digital twin" has become an element of the Fourth Industrial Revolution.

It is suggested that it is expedient to create a "digital twin" of the subsystem "financial component of entrepreneurial ethics" in state policy and business policy for regulating the development of ecosystems based on option modeling. Digital twins of subsystem interaction are prototypes of tools in the "ecology-state-corporations-society" format. Using such tools, it is possible, in particular, to analyze the cycles of entrepreneurial ethics in the field of economics and management, their reactions to various impacts or changes.

The goals of the digital twin of ethical entrepreneurship in the development of strategies for the sustainable development of the region, the country are: modeling options for changing the volume and share of environmentally friendly products, the opening of new educational programs on business ethics and corporate social responsibility, the introduction of innovations, etc.

It is important that the digital twin of ethical entrepreneurship allows you to use predictive analytics, conduct virtual experiments and predict the behavior of objects.
We consider the digital twin as a system of information technology, analytical and organizational means of collecting, storing and processing information about the main subjects and processes. At the same time, the digital twin of ethical entrepreneurship in the format "ecologystate-corporations-society" is a part, a subsystem of the digital twin of the sustainable development system [9]. Therefore, modeling and forecasting make it possible to make an informed choice of their development strategy due to the mutual influence and interaction of the components of this format.

Digital twins of the Ecology-Government Business-Society system are designed not only to develop a financial strategy to support management decisions, but also to monitor and analyze the condition of objects. For example, the supply chain of the agricultural system, like the vast majority of other systems, is very fragmented: manufacturersdistributors-retail network (food companies-)consumers, which makes it urgent to solve the problem of combining these components. The Tilloplatform.Markt, the launch of which was discussed at the agricultural business forum "ProAgroTalk 1.0", could unite all participants in the agricultural sector.

It should be added that entrepreneurial ethics throughout the supply chain helps to reduce the amount of waste, makes the entire chain more transparent for consumers, and markets more reliable for producers. Such an approach will also be useful if a new wave of pandemic strikes the world, and if there is a shortage of vital goods, the use of technologies such as blockchain will help minimize the threat of their shortage, thanks to the ability to track the supply of goods throughout the chain, and the chain itself would gain flexibility during such an epidemiological crisis.

Blockchain is a decentralized registry technology in which all participants in the supply chain from manufacturers to sellers, including all intermediate suppliers, can track the movement of goods in chronological order. When one interested party updates information about a product, everyone else also gets access to this data. For example, in agricultural practice, with a modernized supply chain, seed producers can cooperate with farmers to solve the problems of processing enterprises and, ultimately, consumers. These postulates can change the agricultural production market with information on compliance with the ethics of economic relations of agribusiness with consumers, partners, government and become an intersectoral standard of 
ethical entrepreneurship. Each participant in the chain: like a company, a bank, an insurer and an investor, after analyzing the issuers of analogues and their policies, auditing their internal policies, assets and projects, will be able to adjust their business models based on the comparability of disclosed information related to environmental ethics.

Optimization of relations between producers of products in the format of ethical entrepreneurship requirements, assuming a set of criteria and indicators of specific individual actions of an individual economic entity, has a direct impact on the environment, and the use of innovative technologies and digitization, along with both historical and cultural aspects, and with an understanding of the concept of traditional and regional products, allows the national economy to produce new types of environmental products. All of those are able to increase the demand of buyers. The active participation of society in solving environmental issues and the integration of regional, sectoral, corporate environmental protection programs into the overall system of ensuring environmental safety of the country or region in the context of the transition to new environmental standards will contribute to the implementation of key areas of the national project "Ecology" $[10,11]$.

\section{DISCUSSION}

Since there is not yet a unified system for identifying "green" projects, many business structures lack internal policies related to "green" financing. Because of this, issuers are not ready to evaluate such projects, their risks and issue "green bonds" for them. Despite the fact that ESG factors have become one of the key indicators for investors, there is no single methodology for assigning a rating to companies based on them yet. ESG principles are based on the goodwill of companies, transparency and responsibility. In this regard, it is important to work with corporate clients to inform about the possibilities of "green bonds" and their benefits for companies.

However, the difficulty lies in the fact that in some cases it is difficult to clearly identify which of these competing segments of the green bond market are the most promising in modern conditions. At the same time, both the volume of data increases, and the need for their high-quality processing and reliable conclusions that can be relied on when making decisions. In addition, each project requires a professional solution from the standpoint of business ethics for checking counterparties, marketing, investment analysis, etc. As a result, there is a demand for analytical systems in which high-quality information is combined with analytical tools. This topic is relatively new for the market, where issuers incur additional costs for obtaining an independent opinion, evaluating "green" projects and providing additional reporting. One of the mechanisms for reimbursing these costs may be a more favorable coupon rate, but the level of "awareness" of Russian investors is not yet high enough to invest in less profitable bonds. Measures to stimulate "green" financing not only for investors, but also for issuers, including from the financial sector, can change the situation. For example, the abolition of the mandatory reserve for "green bonds" in the Bank of Russia can significantly stimulate their issuance by financial institutions.

\section{CONCLUSION}

An analysis of entrepreneurial ethics is necessary for the institutional environment of the region, industry and country in the development and implementation of a strategy for financial support for sustainable economic growth. Among the main areas of such research are: assessment of "green" projects and measures to stimulate "green" financing, forecasts, situational analysis; information support of the tasks of situational analysis and forecasting of socio-economic processes. As well as modeling (market, financial, scenario); analysis of the market for ecological products (assessments and forecasts), identification of new needs and markets, assessment of the potential of markets, modeling of not yet formed markets; benchmarking (market analysis based on socio-economic benchmarking statistics and business climate).

\section{AUTHORS' CONTRIBUTIONS}

Yuri A. Levin analyzed the role of ethical entrepreneurship in the green economy including highlighting the main characteristics of ethical entrepreneurship and proposed to consider the digital platform as an information and economic structure that ensures the organization of algorithmic effective interaction of its participants by providing information infrastructure as well analyzed the multi-purpose opportunities of digital twins with mutual influence of the ethical entrepreneurship system subjects. Olga P. Ivanova identified the possibilities of creating a "digital twin" of government policy and business policy to regulate the ecological type of ecosystems financing in the context of strategies for sustainable growth of the 
national economy, regions and industries based on optional modeling. Galina Yu. Fomina analyzed the structure of ethical entrepreneurship as a set of strategic analysis institutes, financial institutions, business models, and digital platforms forming management decisions on sustainable development and implementation of ESG. Andrey V. Volkov stated that the ecosystem supply chain is fragmented, and therefore it is necessary to create a digital platform to unite all participants in responsible investment in the ESG format.

\section{REFERENCES}

[1] H. Daly, J. Farley, "Ecological Economics: Principles and Applications", Washington, DC: Island Press Publishing, 2003.

[2] Yu.A. Levin, G.Yu. Fomina, A.V. Volkov, "Conceptual provisions of agricultural ethics and their practical implementation", International Agricultural Journal, 2021, vol. 6(384), pp. 65-68. (In Russ.). DOI: https://doi.org/10.24412/2587-6740-2021-6-6568

[3] V.I. Gurman, N.E. Kulbaka, E.V. Riumina, "Programs for accounting for the environmental component in the system of national accounts" [Programmy ucheta ekologicheskoi sostavliaiushchei $\mathrm{v}$ sisteme natsionalnykh schetov"], Economics and Mathematical Methods, 1996, vol. 32(10), pp. 111-120. (In Russ.).

[4] E.S. Kondyukova, E.G. Shershneva, N.L. Savchenko, "Green banking as a progressive model of socially responsible business", The Manager, 2018, vol. 9(6), pp. 3039. DOI: $10.29141 / 2218-5003-2018-9-6-3$

[5] P.B. Thompson, "Agrarian Vision: Sustainability and environmental ethics",
Lexington: The University Press of Kentucky, 2010.

[6] R. Costanza, J.D. Erickson, J. Farley, I. Kubiszewski, "Sustainable Wellbeing Futures: A Research and Action Agenda for Ecological Economics", Cheltenham: Edward Elgar Publishing, 2020

[7] R.A. Kamaev, Yu.A. Levin, M.A. Sokolnikov, "Formation of technological structures in the textile industry: production and regional aspects", Proceedings of higher education Institutions, Textile Industry Technology, 2019, vol. 1(379), pp. 5-12. (In Russ.).

[8] M. Arkhipova, V. Sirotin, V. Afonina, "Cooperation in R\&D as a Leading Indicator of Innovative Activity Growth", International Journal of Economics \& Business Administration, 2019, vol. 7(S1), pp. 242-257. DOI: https://doi.org/10.35808/ijeba/389

[9] O.P. Ivanova, Yu.V. Daneykin, V.M., Tumin, V.A. Trifonov, Yu.A. Levin, "Strategy of development of the regional ecosystem Education - Science - Industry", in Proceedings of the ISPC "Russia 2020 - a new reality: economy and society" (ISPCR 2020), 2021, pp. 23-26. DOI: 10.2991/aebmr.k.210222.005

[10]E.A. Tretyakova, D.V. Shimanovskii, "Social welfare and eco-economic dynamics: an analytical model", Studies on Russian Economic Development, 2020, vol. 31(1), pp. 108-112. DOI:10.1134/S1075700720010165

[11]R. Shpakova, K. Kusatov, S. Mustafin, A. Trifonov, "Changes in the nature of longterm fluctuations of water flow in the subarctic region of Yakutia: a global warming perspective", Geosciences (Switzerland), 2019, vol. 9(7), p. $287 . \quad$ DOI: 10.3390/geosciences 9070287 